\title{
Service delivery for microsystems production: a study
}

\author{
Christopher Durugbo*, Ashutosh Tiwari and Jeffrey R. Alcock \\ School of Applied Sciences, \\ Cranfield University, \\ Bedfordshire, \\ MK43 0AL \\ United Kingdom
}

Corresponding author email: c.durugbo@ cranfield.ac.uk

Telephone: +44 (0) 1234750111 Ext 5656

\section{Service delivery for microsystems production: a study}

\begin{abstract}
This paper presents the findings of an investigation into the industry practice of service delivery within microsystems technologies (MST) (also known as micro-electro-mechanical systems (MEMS)) production. A study was undertaken to evaluate $100 \mathrm{MST}$ companies that deliver integrated products and services i.e. a product-service system (PSS).

The aim of the study is to: (i) analyse the main types of services delivered by MST companies, and (ii) make recommendations for improving MST production. The PSS approach to production and manufacturing is introduced and used to evaluate the current state of service delivery within MST production. The findings of the study are then used to make recommendations for improving future MST production.
\end{abstract}

Keywords: Microsystems technology, Micro-electro-mechanical systems, Production management, Product-service systems, Value creation, Service, Business model 


\section{Introduction}

\subsection{Research background}

Within production for MST, the need to deliver services to aid and enhance the use of MST is crucial to the production strategy or business model adopted by a MST company. This is because MST production is underpinned by services delivered through research and development competence houses and design houses (Wilkinson, 2000). Services delivered by MST companies centre on technical expertise and extensive knowledge of MST management and market, and years of experience in the MST industry. MST production employs miniaturisation and integration techniques which show significant similarities to those of integrated circuit processes (Haskard et al., 1995). However, MST differs from microelectronics as it exploits a wide range of phenomena; not just electronics - such as electromagnetism, optics, fluidics, mechanics, tribology, and spectrometry just to mention a few. Consequently, due to the highly technical nature of MST production, very rarely is an MST offered to MST customers without the delivery of some form of services.

\subsection{Aim of paper}

This paper evaluates the current state of service delivery within MST production. The aim of the paper is to: (i) analyse the main types of services delivered by MST companies, and (ii) make recommendations for improving MST production. In order to accomplish this, the product-service system (PSS) approach to manufacturing and production will be introduced and used to carry out a study to evaluate service delivery within MST production. Recommendations based on the findings of the study will then be used to suggest possible areas for improving future MST production.

\subsection{Product-service systems and microsystems production}

A PSS has been defined as 'an integrated product and service offering that delivers value in use' (Baines et al., 2007). It involves making use of social constructs (organisations) that detail the network of actors, roles and scenarios for 
delivering a blend products and services (solutions) that are largely dependent on the domain of application, investment and resources (Durugbo et al., 2009).

A PSS is a business model based on value propositions according to product, use or result orientations, as shown in Fig. 1 (Tukker, 2004; Schuh et al., 2008). In product-orientation, the company offers the sale of products and also opens channels with the customer for access to additional services such as upgrades whereas in use-orientation, the company maintains the rights to a product for use in a service environment made accessible to the receiver via services such as product leasing. Result- orientation involves the company delivering contents of a service to the customer, independent of product choice in schemes such as payingper-unit service.

A PSS also offers a generic approach to production that can be applied to identify gaps and opportunities for service creation and production improvements across industries and industry sectors such as MST production (Durugbo et al., 2010). This is in contrast to the production classification by Yole Développement (2009) that captures seven main groups (made up of system manufacturers with internal fabrication facilities, system manufacturers with external fabrication facilities, fabless companies, contract manufacturers, engineering and design, off-the-shelf manufacturers and foundries) for MST production or Wilkinson's (2007) industry structure that identifies a four-tier arrangement (consisting of foundries, component manufacturers, device manufacturers and instrument /equipment builders) for the MST industry. Whereas these proposed classification and industry structure are based on the interaction of consultants with industrial companies, the PSS approach systematises production in companies irrespective of the industry sector.

\section{Insert Figure}

However, the PSS approach is hindered by the absence of a comprehensive standard model for characterising PSS structure and behaviour (Durugbo et al., 2010). Furthermore, the adoption of the PSS approach by companies may offer little or no potential for system innovation in sectors such as: the tools industry, manufacturing firms, telecommunication companies, ship makers, paper mills, and the automotive industry (Schuh et al., 2008; Tan et al., 2010; Sundin et al., 
2010; Williams, 2007). It is for this reason that in some cases it may not be commercially or economically sensible to apply a PSS (Manzini and Vezzoli, 2002). The key therefore is to first determine if a PSS is right for the company and its customers or market sector. Also, studies such as Williams (2007) have shown, it is important to determine the level of diffusion of PSS value propositions. Differences in companies based on PSS value propositions can then be used to suggest ways of realising system innovation (Williams, 2007).

Nonetheless, the PSS approach is suited to this study because unlike existing classifications and industry structures within the MST domain, the PSS approach can be applied to evaluate current practise in service delivery for improving MST production in terms of two key factors: service engineering that highlights the importance of creating and delivering services for added customer value during the life cycle of a product, as shown in Fig. 2, from the engineering phase through to the usage phase and the recycling/disposal phase (Aurich et al., 2006; Sakao and Shimomura, 2007; Tan et al., 2010), and industry partnerships for relationships and networks based on multi-actors collaborations (Durugbo et al., 2010).

\section{Insert Figure}

Within the context of MST production, these factors have played key roles in fostering the growth of the MST industry.

Services engineering plays a key role in enabling access to the MST industry through operations, management and support activities such as design and s upply services (Devlin, 2004) and field services (Lin et al., 2005). These services support MST production processes in terms of design consultancy, system-level testing and prototyping. By applying services during MST life cycles, industry growth has been promoted in schemes where non-recurring engineering costs are reduced to realise shorter production times as identified by Wilkinson (2007). Services related to MST life cycle are also required to assess the environmental consequences of design decisions (Schischke et al., 2005).

Partnerships are the basis for alliances involving foundry companies, equipment and material suppliers, software vendors, academic institutions and governmental organisations (Fujita, 2007). These alliances according to Fujita (2007) are vital to 
minimising fabrication costs so as to promote small-volume-large-variety production. Production management partnerships such as fabless-foundry partnerships are also important for enhancing coordination and information flow for information sharing (Guo et al., 2007).

Since MST production is moving from a 'surprise to an enterprise phase' (Fujita, 2007) with recent projections by consultancy firms such as Yole Développement (2009) forecasting continuous growth and capital returns in the MST industry, it is therefore important to evaluate current practice in MST production so as to understand service delivery needs.

This understanding of service delivery can be applied by MST companies to extend the life of MST based product, improve MST production times and costs, and provide added value for MST customers.

The focus of this paper is to evaluate current practise in service delivery within MST production. The paper plans to contribute to knowledge by: evaluating service delivery within MST production using the PSS approach as a guide, and making recommendations for improving future MST production.

\subsection{Structure of paper}

The remainder of this paper is structured as follows: $\$ 2$ describes the methodology for the study to evaluate service delivery within MST production, $\S 3$ presents the findings of the study while $\$ 4$ highlights and discusses possible areas for future MST production improvement.

\section{Research method}

The study to evaluate MST production based on the PSS approach was undertaken in four stages: sample selection, network identification, data collection and data representation.

\subsection{Sample selection}

During the first stage, sample selection, a total of 100 MST companies were sampled for the study. These companies are headquartered at locations in Europe 
(56\%), North America (38\%) and Asia (6\%) as shown in Fig. 3. The sample was based on a random selection of member companies of the MEMS Industry Group (http://www.memsindustrygroup.org), IVAM (http://www.ivam.de) and SEMI (http://www.semi.org). MEMS Industry Group, IVAM and SEMI are international associations for companies aiming to carry out business transactions within the MST industry.

The sample was selected for use in this study to provide a representative sample of the MST domain and all sampled companies delivered integrated MST products and services offerings.

\section{Insert Figure}

An initial inspection of sampled companies revealed four main product sectors within which MST companies operate to offer a wide range of customer solutions. Of the sampled companies $78 \%$ offered micromechanical solutions, $72 \%$ offered micro-optical solutions, $69 \%$ offered microfluidic solutions and $40 \%$ offered radio frequency/microwave solutions, as shown in Fig 4. In the figure, the micromechanical companies were identified from groups $\mathrm{a}, \mathrm{b}, \mathrm{c}, \mathrm{d}, \mathrm{f}, \mathrm{g}, \mathrm{h}$ and $\mathrm{l}$ (i.e. $31+22+4+1+7+1+1+11=78$ ) whereas the micro-optical companies were captured from groups a, b, c, e, f, i, j and $\mathrm{m}$ (i.e. $31+22+4+0+7+3+0+5=72$ ). The microfluidic companies were ascertained from groups a, b, d, e, g, i, k and n (i.e. $31+22+1+0+1+3+0+11=69)$ whereas the radio frequency/microwave companies were captured from groups a, c, d, e, h, j, k and o (i.e. $31+4+1+0+1+0+0+3=40$ ).

\section{Insert Figure}

An inspection of company documentation and reports also revealed that MST production was characterised by the delivery of five types of product offerings to business-to-business (B2B) customers (mainly original equipment manufacturers (OEMs) and university / research institutions):

1) Chips in the form of bare die created using material such as plastics, ceramics, silicon and adhesives.

2) Miniaturised and integrated devices (or micro-integrated devices) that contain chips and are packaged to perform microscopic tasks or are used in 
micro-instruments and micro-machines. This group also contains interconnections/packaging that are required for protecting devices and chips, and for interactions with the environment

3) Micro-instruments developed from chips and micro-integrated devices, and applied for specialised tasks such as Lab-on-a-chip systems that are used for biochemical analysis.

4) Microfabrication machines and microfabrication machine parts used to manufacture chips, micro-integrated devices and micro-instruments based on technologies such as bulk and surface micromanufacturing, LIGA (Lithographie, Galvanoformung, Abformung) process etc

The study also identified intangible products associated with design and development processes within the sampled companies. Design processes centre on activities involving the use of computer-aided design (CAD) tools to virtually generate, simulate, verify and validate MST architectures. Development of MST products focuses on the use of fabrication capabilities and technical expertise of MST engineers. Two main intangible products offerings were identified for MST design and development processes:

1) MST designs and Intellectual Property (IP) detailing the architecture or the process for fabricating chips, micro-integrated device, microinstruments and micro-machines.

2) MST software packages for generating, simulating, verifying and validating MST design.

\subsection{Network identification}

Four possible collaborative actors that deliver services for added customer value during MST production, as shown in Fig. 5, were identified based on the companies examined for this study. These actors include developers, designers, consultants and marketers that assume roles for scenarios in a value network (value-net) of MST suppliers to deliver products and services.

The survey sample was made up of 77 developers, 7 designers, 10 consultants and 6 marketers. Companies also assumed multiple roles (3 designers and all sampled developers also assumed consultancy roles, and 3 developers also acted as designers when required to deliver a complete MST based product). 
Developers consist of foundries and component, device and instrument manufacturers as captured by Wilkinson's (2007) four-tier arrangement of the MST industry. In addition, this study also identifies prototype manufacturers as developers designed to support MST production by offering physical prototypes of MST products prior to mass-production. The results of prototype testing aid in the transformation or modification of designs into MST based products for use in consumer products.

\section{Insert Figure}

The term designers is used in this study to identify software companies that design and deliver a wide range of commercial computer-aided design (CAD) packages that are summarised in Table 1. These tools incorporate a wide range of modules for creating complex MST models, device simulation, and for verifying the properties of MST using numeric solvers, compatibility with IC simulators etc.

\section{Insert Table}

Designers are also used in this study to identify intellectual property (IP) solution companies. An IP is a predesigned, pre-verified, complex functional block, based on a hierarchical design for the development of MST based products. An IP solution usually involves a complete process and device design for specific applications such the MEMS microphone and biochips. These IP solutions are used to realise various configurations for MST architectures at the chip, package or board level.

Of the 77 developers sampled in this study, 50 offered chips, 59 manufactured micro-integrated devices, 59 delivered micro-instruments, and 9 were microfabrication machine manufacturers while 31 owned foundries. Also, of the 7 designers sampled in this study, 3 offered IP solutions, 3 offered CAD packages and 1 company offered both IP solutions and CAD software packages for designing and developing chips, micro-integrated devices and micro-instruments. The study also identified and examined two other industry actors designed to support MST design and development: consultants, and marketers. 
MST consultants offer various organisational, technological, economical and human factors focused advice on MST start-up, production, recruitment, technologies, education and management.

Marketers are distributors or suppliers concerned with the buying of products from developers and the selling or distribution of products to customers or end users. An understanding of MST and extensive knowledge of MST products are important technical skills of marketers. The sale of MST based products is either carried out by a specialist distributor focused on microfluidic, microoptical or micromechanical technologies, or by broad line distributors that offer wide range of MST based products.

Fig. 5 also identifies development activities by a wide range of research institutions (largely universities) that investigate MST designs for the development of prototypes. These institutions, in order to engage in MST production, typically assume other roles such as consultancy, MST design or MST development. Although, university institutions are not investigated in this study, it is important to note their importance to the industry for generating spin-off companies. In this study, at least $24 \%$ of the sampled companies were spin-offs from research institutions, $4 \%$ were start-ups by multinational companies whereas, $13 \%$ were subsidiaries or companies set up by major enterprises and conglomerates.

\subsection{Data collection}

The second stage, data collection, was based on an inspection of company profiles by means of technical documentation, the World Wide Web (WWW) and available company publications such as corporate reports and press releases. Telephone calls were also used in a few cases to source information on the nature of MST production within the sampled companies. Each of the 100 companies was successively evaluated to identify delivered services, and to reveal possible value propositions based on the PSS orientations within the sampled companies. 


\subsection{Data representation}

The third stage, data representation, involved making use of cross-tabulation techniques to present the findings of the study based on the identified product types, delivered services and PSS value propositions.

As a guide for this phase, the wide accepted and cited model for PSS by Tukker (2004) was used to categorise and analyse MST services. The model lists PSS value propositions based on three main categories identified as product-, use- and result- orientation, as shown in Fig. 1.

\section{Research findings}

The study showed that a wide range of services, as shown in Table 2, was delivered by the sampled companies to support the life-cycle of MST products. The table summarises the services of the selected sample according to the various forms of value propositions identified in (Tukker, 2004). Each PSS value proposition in the MST industry will now be highlighted.

\subsection{Product-related service (value proposition 1)}

Of the sampled MST companies, product-related service (i.e. the sale of a product inclusive of services that are required for the use of the product) was offered by all the sampled MST developers (i.e. 77\% of sampled companies). The common product-related service among chips, micro-integrated device and microinstruments manufacturers, was a prototyping service to physically test and simulate MST. The study also revealed that all micro-machinery and microinstrument developers also offered value propositions based on service contracts during the sale of products, with warranty, field support, installation, relocation and contract options for services such as maintenance and repair. Field support describes the process of sending out technicians to undertake specific tasks to support such as machine checkups and system testing. Additional product-related services were offered by microfabrication machines and micro-instrument manufacturers in the form of software upgrades to improve machine use, and hardware upgrades based on continuity in machine family lines such as plasma etch and deposition platforms and systems. Diagnostics and work-in-process 
services are usually incorporated in microfabrication machines and microinstruments for added value and for maintaining an audit trail to assist engineers in routine maintenance and fault diagnosis.

Insert Table

\subsection{Training, advice and consultancy (value proposition 2)}

The study showed that offering advice on the efficient use of a product is realised in three different forms: general advice/consultancy for MST, training for MST design, and training in the use of MST equipment (machinery and instrument) for MST development.

$73 \%$ of the sampled companies for this study offered a wide range of general consultancy services focused on fabricated products i.e. chips, micro-integrated devices, micro-instruments and micro-machines. Consulting offered by companies focuses on issues such as state-of-the-art market surveys, technology strategy, failure analysis, cost of start-up, solicitation of venture capital, types of technology, feasibility studies, and so on. These activities are designed to promote profitable manufacturing operations, sustainable system production and affordable customer solutions. Advice on the other hand centres on the selection and use of products to carry out multiple tasks. In some cases where MST were marketed as 'tools kits' that performed multiple functions such as microchemical and microbiological analysis, companies also offered advice on the purchasing and the incorporation of additional modules to perform other tasks such as temperature control, electrical and optical measurements, and reagent introduction.

MST developers also provided the opportunity for customers to access an online support service designed as walkthroughs for product related issues such as how to fix bugs or use device features. In other cases, customised user accounts were provided to manage access to a repository service for technical literature detailing product specification and for describing application technologies to support operability.

In terms of training for MST design, the study revealed that $15 \%$ of the sampled companies focused on a wide range of aspects associated with MST to offer support for various products. 8 out of the 50 chip manufacturers, 10 out of the 59 
micro-integrated device manufacturers and 11 out of the 59 micro-instrument manufacturers focused on training for current/emerging design paradigms in MST. These design paradigms range from Network-on-chip (NoC) for improve communication in system architectures, to Hardware/Software (HW/SW) codesign for dealing with complexity in the design of MST. Similarly, 6 out of the 7 sampled MST designers offered training courses and resources for creating designs (CAD engineers) and for applying IP blocks to realise MST architectures (IP solution providers).

The study also revealed that $14 \%$ of the sampled companies most of whom were microfabrication machine manufacturers, offered workshops, training course and seminars on the use of supplied machinery and related technologies such as advanced fluids, combustion and radiation hydrodynamic analysis.

\subsection{Product lease and product renting or sharing (value proposition 3 and 4$)$}

In the sampled MST companies, maintaining ownership of a product that is leased out to a receiver based on unlimited and exclusive access to use of the product, was identified among all the designers ( 7 companies) selected for the study (CAD engineers and IP solution providers).

CAD packages are typically offered to customers based on a renewable licence, usually one year. Furthermore, these CAD packages are offered with varying degrees of functionalities and features depending on the nature of the package option (and cost). The package options centre on various functionalities for physical, device, system, and process modelling that are applied to: simulate MST architectures, create layout masks, create 3D models of physical properties and define fabrication processes. Most CAD systems incorporate numeric solvers for creating, analysing and verifying the properties of MST, and for creating complex MST models that are compatibility with IC simulators.

For IP solution providers, this value proposition is the business model on which their companies are shaped. IP solutions are licensed out to companies based on service terms (normally yearly). By using technologies such as the internet and information technologies (IT) these companies are delivering tangibles (IP and CAD package execution files) for customer solutions without physical 
components, thereby minimising material input and maximising revenue generation.

In the sampled companies, the renting out of a product with controlled, limited and sequential access to a receiver (product renting and sharing) was also identified in $26 \%$ ( 8 out of 31 ) of developers with manufacturing foundries. These identified foundries were owned by large research institutions set up by industry, academic and government collaborations to promote MST research, or set up as subsidiaries of a corporation composed using in-house or externally acquired facilities. Value proposition in these foundries is based on sharing fabrication capabilities with other sectors of a corporation or based on leasing parts or blocks within the foundry to smaller businesses - usually start-ups from the leaser. At least one case was found where a company (a start-up) rents a block in a foundry facility (the research institution from where the start-up was created), employing its own fabrication team and delivering solutions based on its technological capabilities.

\subsection{Activity management/outsourcing (value proposition 5)}

Outsourcing as a value proposition can be defined as a scheme whereby functions or processes for customer solutions are procured from an outside source. For instance, a developer may procure the services of a marketer to distribute its products or a micro-integrated device manufacturer may procure a foundry service to manufacture its chips, packaging and assembly. For this study, $8 \%$ of sampled companies (mostly micro-integrated device manufacturers) outsourced their fabrication processes to foundries whereas $15 \%$ of sampled companies (mostly foundries) outsourced the distribution and sales of their products to marketers. In MST production, this is usually done for three main reasons: firstly, when a customer places a very large order (usually in the order of $10^{6}$ or $10^{9}$ ) and a company lacks the capabilities to fulfil the order, secondly, to take advantage of an outsourcers capabilities as a means of shortening the time to market a product, and thirdly, as a cost cutting or saving measure that allows the outsourcer to concentrate on improving their capabilities and streamlining their in-house processes of research, development and application (R-D-A) for MST. 


\subsection{Pay-per-service unit (value proposition 6)}

All the fabrication (fab) companies and manufacturing foundries ( $31 \%$ of sampled companies) deliver the pay per service unit value proposition (i.e. selling the output of a product instead of the product itself). The product in this case is the micro-fabrication machine and instruments in the foundry (or 'fab') whereas the service unit include wafers, chips, micro-integrated device, packaging, interconnections and so on. An MST foundry is a service facility with a cleanroom environment that houses microfabrication and micromanufacturing tools that are employed to produce MST. Foundry services usually involve design, testing, process, production, package and assembly support in attempt to deliver a 'one shop mass production process' capability. The need to support these highly technical functions probably accounts for why $90 \%$ (18 of the 20) of foundries in this study also offered consultancy and advice services.

\section{Discussion}

Motivated by the findings from the studied companies, a set of recommendations are now discussed. These recommendations concentrate on service delivery analysis and management for improving current practise within MST production.

\subsection{Service delivery analysis for microsystems production}

As shown by this study, specific value propositions of the PSS model are realised by the different actors that have been identified in Section 2.2. It is however important to note that the examples and identified value propositions are not intended to give an exhaustive analysis of the industry. Rather, it is designed to promote subsequent and wider evaluation of industry sectors using the PSS model.

However, a cross tabulation of MST based product types and value propositions of the PSS model as shown in Table 3 suggests possible areas for creating and improving services in the MST industry by introducing PSS value propositions. Some of these value propositions (at least for now) may not be practical or logical. In some other cases, the constraints imposed by form factors or intellectual property may hinder the implementation of a value proposition. 
For instance, the renting or leasing of a chip or die is a value proposition that is not rational. On the other hand the leasing of a foundry or the leasing of machines to promote access to fabrication technologies offers more plausible means for manufacturers to create value during delivery.

\section{Insert Table}

In terms of providing PSS value propositions, functional result (result-oriented) and product pooling (use-oriented) as shown in Table 3 are noticeably absent in the sampled companies. The functional result value proposition centres on a provider delivering the result of product based on agreement with a client. In industry, this value proposition could be particularly beneficial for instrument manufacturers where the measurements and analysis of phenomena of such as DNA analysis or cell handling and sorting in microfluidic applications are the functional results required of a product. Product pooling is similar to product sharing and leasing in that it centres on the control of a product. It is however unique and different because it is based on the concurrent use of a product.

Also, a summary of the services, from Section 3, suggests that service delivery for MST production has predominantly centred on providing engineering, production and engineering life-cycle phase services, as shown in Table 4. The life-cycle phase services contained in the table are taken from Fig. 1 in which the actual product life cycle has been compared with the manufacturers' and users' views of life cycles. Table 4 also shows that services within the MST domain have also supported product and service design as well as product purchasing and usage. However, there is a lack of services to support the end-of-life phases for recycling, spare parts manufacturing, product reengineering and disposal.

Consequently, there is a need for greater awareness and studies on MST end-oflife phase services to minimise environmental impacts of MST production. Awareness and accessibility to MST is a challenge for the MST industry in relation to market penetration where consumers are cautious in the use of new products (Ohlckers and Jakobsen, 1998).

Compliance with environmental standards offers a unique opportunity for companies to build customer confidence, making MST products more desirable and reinforcing the 'win-win' scenario of life cycle engineering for customers and 
manufacturers (Mont et al., 2006). Customers 'win' due to affordable solutions and costs that spread across the product-life cycle whereas manufacturers 'win' due to profitable operations and efficient resource use. There is also a third win scenario (i.e. a win-win-win) in which the environment as an enabler for a PSS wins due to minimised environmental impacts of MST production.

Insert Table

Studies are therefore required to investigate and analyse key life cycle costing and assessment issues that affect, economical and ecological aspects of MST production. Future work may also assess which of the PSS has been the most profitability for the MST sector.

\subsection{Service delivery management for the microsystems industry}

As earlier mentioned, the sample for this study was based on members companies of organisations for companies aiming to carry out business transactions within the MST industry. Further analysis of company documentation and websites suggested that MST coalitions provided the main means for the management of service delivery, particularly for outsourcing tasks. MST coalitions are described here as cooperative ventures and associations set up among MST manufacturers for managing various stages of production or for promoting the education and commercialisation of MST. Coalitions for MST production may be set up for delivering complete customer solutions such as INTEGRAM ${ }^{\mathrm{TM}}$ in Europe and CMC in Canada, or for investigating research needs of MST such as the MEMS Applications for Defence (MEAD) consortium.

Collaborative partnerships between industry and academia are common and evident by regular start-ups and spin-offs from academia to industry and research programs involving companies and universities. Consequently, the recommendations made in this subsection are mainly for academic research to theoretically ground and improve current industry practise. Following the evaluation of the sampled companies, two main challenges for academia were identified to: investigate and model collaborative networks for MST production, and to explore service delivery to standardise MST operations and interoperability 
of MST product families for design modularity and continuity within the MST industry.

In this study, a high-level model of the MST industry structure -an MST value network has been captured based on MST companies and actors assuming roles as consultants, designers, developers and marketers. In this network, companies could assume roles to reduce costs of production, to promote small-volume-largevariety production and to deliver tailored and affordable customer solutions. The MST value network could also serve as a foundation for low-level models of MST partnerships such as collaborative networks. Collaborative networks are a novel research discipline motivated by challenges faced by modern businesses and scientific institutions (Camarinha-Matos and Afsarmanesh, 2004). Collaborative networks focus on the use of computer networks to achieve goals that exceed the abilities of collaborating individuals or companies involved in collaborations to provide solutions that are cost effective.

The recommendation for research therefore is to carry out studies that define characteristics of MST collaborative networks and evaluate the implications of companies entering into collaborative networks in terms of cost, production times and MST affordability.

\section{Conclusions}

This paper evaluates service delivery within microsystems technology (MST) (also known as micro-electro-mechanical systems (MEMS)). Services offer avenues for enabling and enhancing the use of products and within MST production, the need to deliver service is motivated by the highly technical nature of MST and continuous market growth of the MST industry. Motivated by these needs, this study makes use of the product-service system (PSS) approach to evaluate and make recommendations for possible future MST production improvement.

The PSS approach to production and manufacturing centres on offering a blend of products and services for product (sale of products with channels for additional services), use (products made available within a service environment) and result (function of product delivered irrespective of product choice) orientations. 
Within the context of MST production, the PSS approach offers potentials for fostering: service engineering to provide added value for MST customers and to extend the life of products, and partnerships to improve production times and costs.

A sample of MST based companies that offer a range of microfluidic, microoptical, micromechanical and radio frequency/microwave MEMS applications was selected to evaluate service delivery within MST production using the PSS approach as a guide. Data was collected from 100 randomly selected MST companies (77 developers, 7 designers, 10 consultants and 6 marketers). Data collected from the sampled companies was based on an inspection of the company websites and on available company publications such as corporate reports and press releases.

In order to capture services for MST production, a value network was identified for the MST industry. The MST value network was made up of developers, designers, marketers and consultants as actors for the delivery of customer solutions. The paper then examined these actors and their roles in the delivery of value propositions based on the PSS approach based on product, use and result oriented approaches.

The study revealed that product-orientation value propositions were offered by $23 \%$ of companies in terms of product-related services and $74 \%$ of companies for consultancy, $15 \%$ of companies for design advice and $14 \%$ of companies for development (or process) advice. Similarly, use-oriented value propositions were offered by $7 \%$ of companies in terms of product lease and $19 \%$ of companies in terms of product renting/sharing whereas result-oriented value propositions were delivered by $34 \%$ of companies in terms of activity management and $32 \%$ of companies in terms of pay per service unit.

Recommendations for possible future MST production improvement were then used to highlight and discuss research challenges for industry and academia in terms of service delivery analysis and management. 


\section{Acknowledgments}

The authors would like to extend their sincere thanks to the Engineering and Physical Sciences Research Council (EPSRC), for its support via the Cranfield Innovative Manufacturing Research Centre (CIMRC), towards the work carried out in the preparation of this paper.

\section{References}

[1] Aurich, J.C., Fuchs, C., DeVries, M.F., 2004. An Approach to Life Cycle Oriented Technical Service Design. CIRP Ann Manuf Technol 53, 151-154. doi:10.1016/S00078506(07)60666-0

[2] Baines, T.S., Lightfoot, H.W., Evans, S., Neely, A., Greenough, R., Peppard, J., Roy, R., Shehab, E., Braganza, A., Tiwari, A., Alcock, J.R., Angus, J.P., Basti, M., Cousens, A., Irving, P., Johnson, M., Kingston, J., Lockett, H., Martinez, V., Michele, P, Tranfield, D., Walton, I.M., Wilson, H., 2007. State-of-the-art in product-service systems. Proc Inst Mech Eng Part B J Eng Manuf 221, 1543-1552. doi: 10.1243/09544054JEM858

[3] Camarinha-Matos, L.M., Afsharmanesh, H., (eds) 2004. Collaborative Networked Organizations. A research agenda for emerging business models. Boston, Dordrecht, London: Kluwer Academic Publishers

[4] Devlin, L., 2004. Design and supply adds value to electronics design services. Microwave Eng Eur (DEC./JAN.), 21-22.

[5] Durugbo, C., Tiwari, A., Alcock, J.R., 2009. An Infodynamic Engine Approach to Improving the Efficiency of Information Flow in a Product-Service System. CIRP IPS2 Conf, 107-112

[6] Durugbo, C., Bankole, O., Tiwari, A., Alcock, J.R., Roy, R., Shehab, E., 2010. Capturing Product-Service Systems across Industry Sectors. CIRP IPS2 Conf: 535-542.

[7] Fujita, H., 2007. Two decades of MEMS - from surprise to enterprise. Proc. IEEE Int. Conf Micro Electro Mech Syst MEMS, art. no. 4433017, 1-6. doi:10.1109/MEMSYS.2007.4433017

[8] Guo, R-S., Su, Y-H, Chiu, S-F., Pai, F-Y., Yeh, C-P., 2007. Evolutionary business models and inter-firm engineering processes between the foundry and fabless in the semiconductor industry. IEEE Int. Symp Semicond Manuf Conf Proc, art. no. 4446820: 275-278. doi: 10.1109/ISSM.2007.4446820

[9] Haskard, M.R., Hariz, A., Marriage, A.J., 1995. Micro engineering-a brief overview. Electronic Technology Directions to the Year 2000: 242-245. doi:10.1109/ETD.1995.403467

[10] Lin, Y-T, Lee I-S and Ambler T (2005) The economics of field service for electronic systems. AUTOTESTCON art. no. 1609107: 84-89. doi: 10.1109/AUTEST.2005.1609107

[11] Manzini, E., Vezzoli, C., 2002. Product-service systems and sustainability: Opportunities for sustainable solutions. UNEP TIE, Paris, [online] http://www.uneptie.org./scp/design/pdf/pssimp-7.pdf [Accessed 10 February 2009].

[12] Mont, O., Singhal, P., Fadeeva, Z., 2006. Chemical management services in Sweden and Europe: Lessons for the future. J Ind. Ecol, 10, 279-292. doi:10.1162/108819806775545295

[13] Ohlckers, P., Jakobsen, H., 1998. Challenges of the emerging microsystems industry. Microelectron J, 29, 587-600. doi:10.1016/S0026-2692(98)00022-6

[14] Sakao, T., Shimomura, Y., 2007. Service Engineering: a novel engineering discipline for producers to increase value combing service and product. J Clean Prod, 15, 590-604. doi:10.1016/j.jclepro.2006.05.015

[15] Schischke, K., Middendorf, A., Reichl, H., Griese, H., Kasper, M., Ong, K., 2005. Green MST design from a designer's perspective: How to base decisions on environmental issues. IEEE Int Symp Electron Environ, 13-18. doi: 10.1109/ISEE.2005.1436984

[16] Schuh, G., Klotzbach, C., Gaus, F., 2008. Service provision as a sub-model of modern business models. Prod Eng Res Devel, 2, 79-84. doi: 10.1007/s11740-008-0084-6

[17] Sundin, E., Ronnback, A.O., Sakao, T., 2010. From component to system solution supplier: Strategic warranty management as a key to efficient integrated product/service engineering, 
CIRP Journal of Manufacturing Science and Technology, 2, 183-191, DOI: 10.1016/j.cirpj.2010.04.007.

[18] Tan, A.R., Matzen, D., McAloone, T.C., Evans, S., 2010. Strategies for designing and developing services for manufacturing firms, CIRP Journal of Manufacturing Science and Technology, 3, 90-97, DOI: 10.1016/j.cirpj.2010.01.001.

[19] Tukker, A., 2004. Eight types of product-service system: eight ways to sustainability? Experiences from SusProNet. Bus Strategy Environ 13, 246-260. doi: 10.1002/bse.414

[20] Wilkinson, M., 2000. Microsystems: How to access the technology. Med Device Tech 11, 24-30.

[21] Williams, A., 2007. Product service systems in the automobile industry: contribution to system innovation. J Clean Prod, 15, 1093-1103. doi: 10.1016/j.jclepro.2006.05.034

[22] Yole Développement, 2009. Status of the MEMS Industry 2009.

\section{Figures}
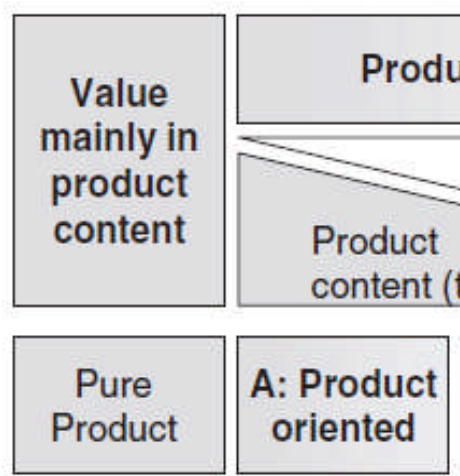

Pure
Product

Pure
Product

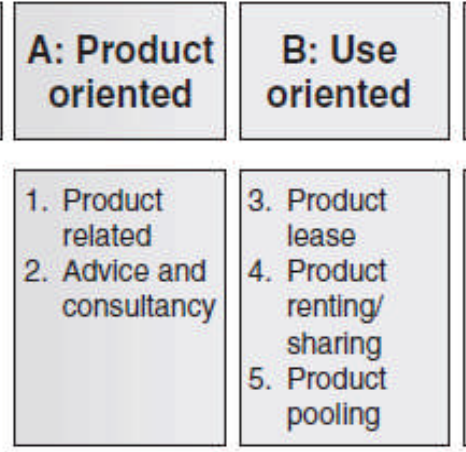

\section{C: Result oriented}

Value mainly in service content

\begin{tabular}{l|} 
6. Activity ma- \\
nagement \\
7. Pay per \\
service unit \\
8. Functional \\
result
\end{tabular}

Fig. 1: PSS categorisation and value propositions [5]

\section{PRODUCT LIFE CYCLE}

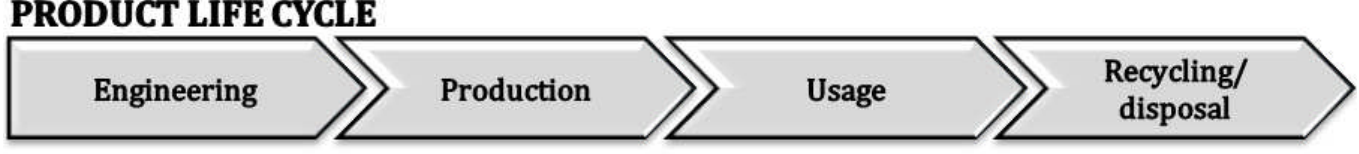

\section{MANUFACTURER'S VIEW}

Service design

\section{USER'S VIEW}

Product purchasing

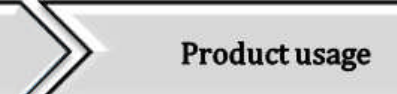

Product disposal

Fig. 2: Service in the product life cycle [11] 


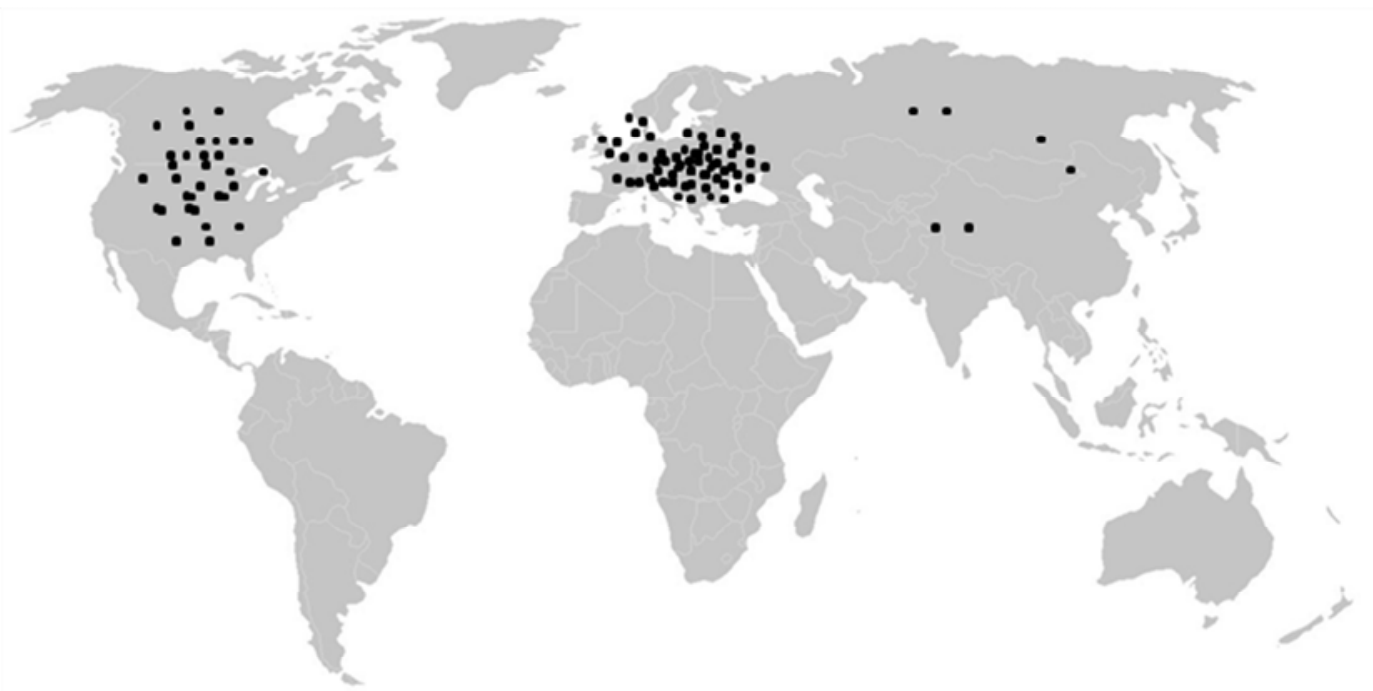

Fig 3: Distribution of sampled companies.

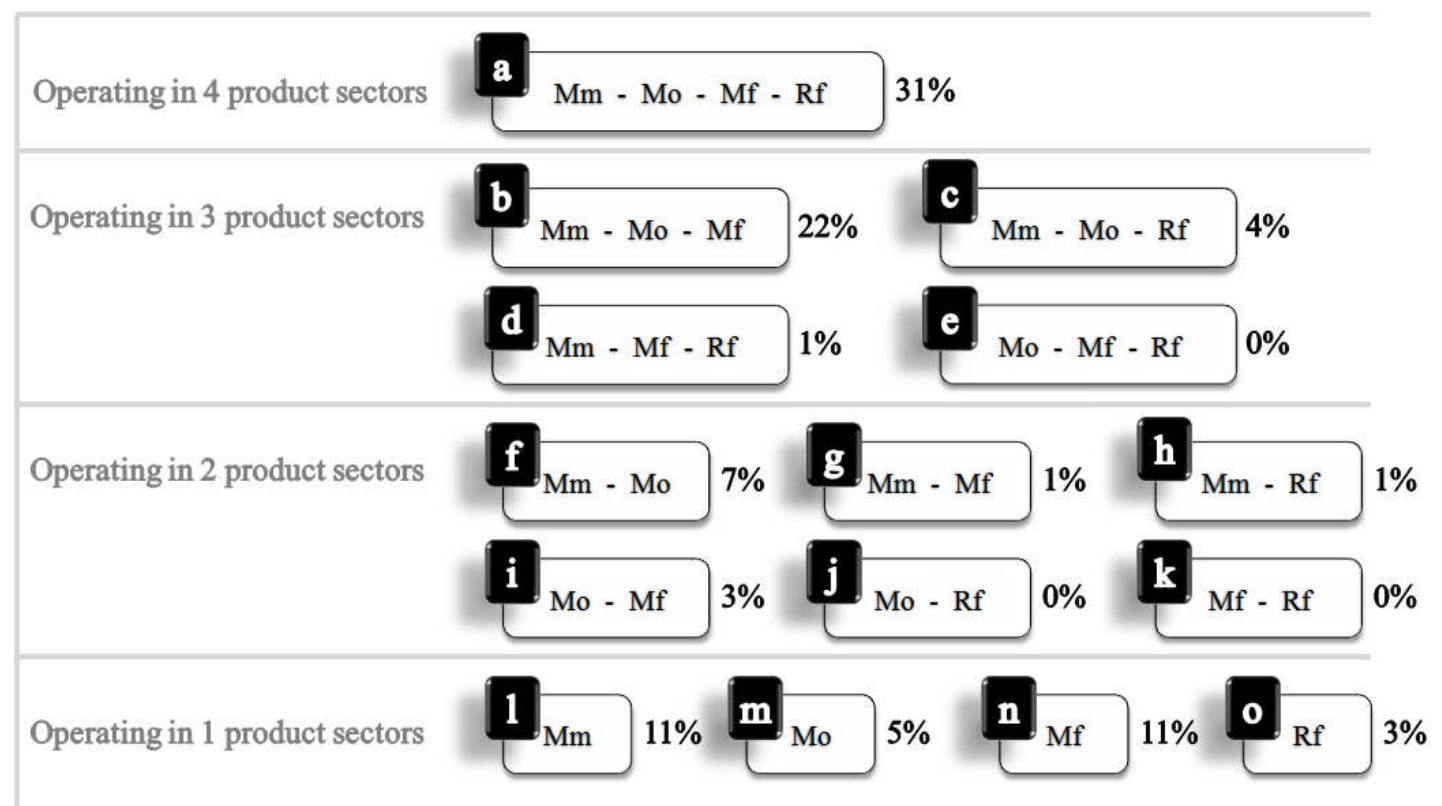

Fig 4: Classification of sampled companies according to product sectors ( $\mathbf{M m}$ - micromechanical, Mo - micro-optical, Mf - microfluidic, and $\mathbf{R f}$ - radio frequency/ microwave). 


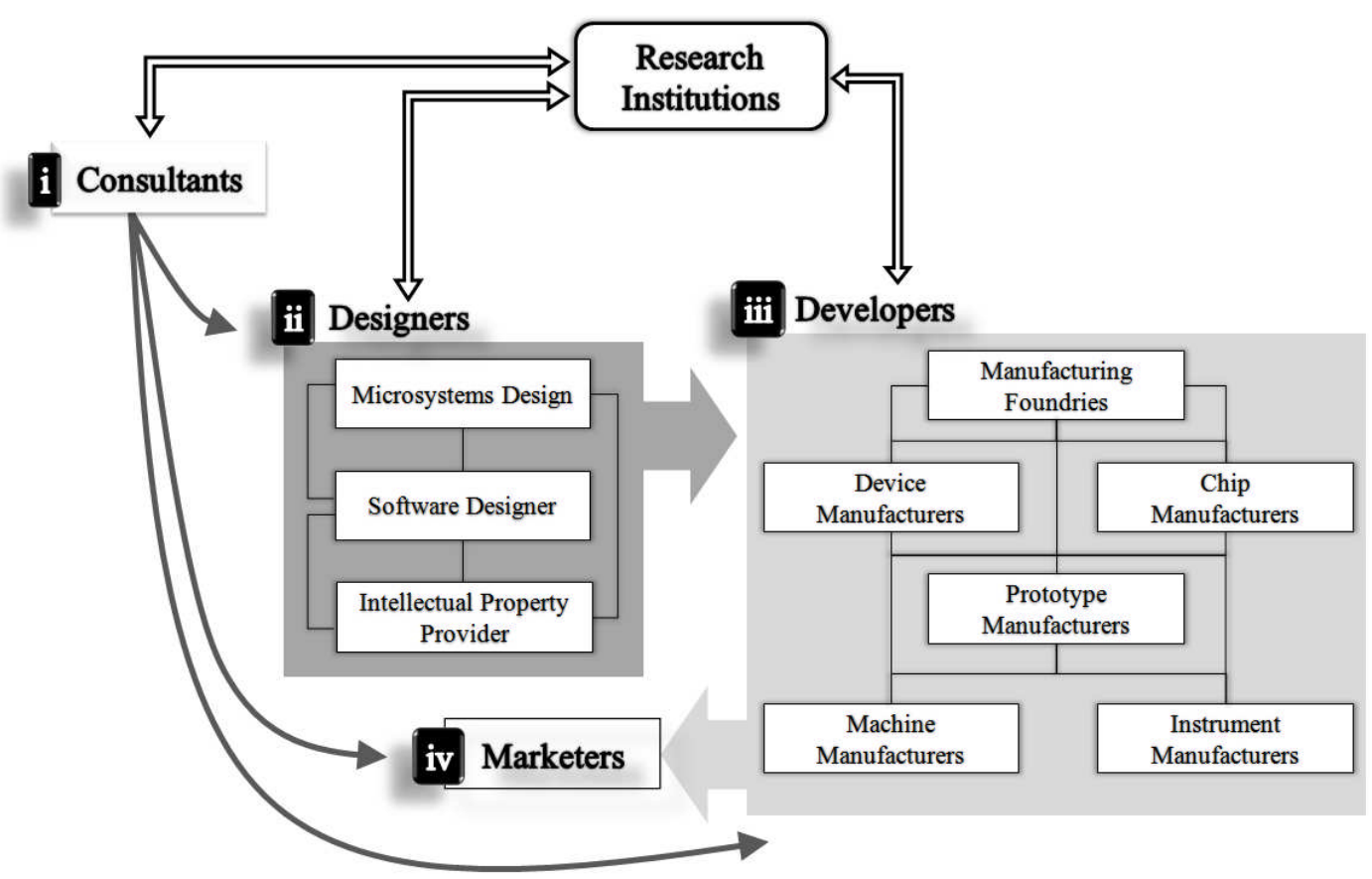

Fig. 5: Microsystems value network: (i) consultants; (ii) designers; (iii) developers; and (iv) marketers 


\section{Tables}

Table 1: Commercially available computer-aided design (CAD) software and packages*

\begin{tabular}{|c|c|c|}
\hline $\begin{array}{l}\text { CAD software /package } \\
\text { (current version) }\end{array}$ & Provider & Website \\
\hline $\begin{array}{l}\text { CoventorWare (2010.000) } \\
\text { and MEMS+ (2.0) }\end{array}$ & $\begin{array}{l}\text { Coventor, Inc. (formerly } \\
\text { Microcosm Technologies, Inc) }\end{array}$ & http://www.coventor.com \\
\hline IntelliSuite (8.6) & Intellisense Inc. & $\begin{array}{l}\text { http://www.intellisensesoftwa } \\
\text { re.com }\end{array}$ \\
\hline MEMS Pro (6.0) & SoftMEMS & http://www.softmems.com \\
\hline OlympIOs (5.2) & Concept to Volume & http://www.c2v.nl \\
\hline $\begin{array}{l}\text { Tanner Tools Pro }{ }^{\mathrm{TM}} \\
(15.02)\end{array}$ & Tanner EDA & http://www.tanner.com/ \\
\hline $\begin{array}{l}\text { CATS® }(2009.03) \text { and } \\
\text { Saber® }(2010.03-1)\end{array}$ & Synopsys & http://www.synopsys.com \\
\hline LinkCAD (5.9.1) & Bay Technology & http://www.linkcad.com \\
\hline $\begin{array}{l}\text { Virtuoso® Analog Design } \\
\text { Environment (L,XL and } \\
\text { GXL) }\end{array}$ & Cadence & http://www.cadence.com \\
\hline $\begin{array}{l}\text { SystemVision }{ }^{\mathrm{TM}} \text {, } \\
\text { BridgePoint and Questa } \\
\text { ADMS }\end{array}$ & Mentor Graphics $®$ & http://www.mentor.com \\
\hline EM3DS (11) & MEMS Research & $\begin{array}{l}\text { http://www.memresearch.co } \\
\text { m }\end{array}$ \\
\hline Simulink® (7.5) & Mathworks & http://www.mathworks.com \\
\hline $\mathrm{dw}-2000^{\mathrm{TM}}(8.40)$ & Design Workshop Technologies & http://www.designw.com \\
\hline CleWin (4) & WieWeb software & http://www.wieweb.com \\
\hline Innovation Station & Altium & http://www.altium.com \\
\hline MemsONE (3.0) & $\begin{array}{l}\text { Mizuho Information and } \\
\text { Research (Inc.) }\end{array}$ & $\begin{array}{l}\text { http://mmc.la.coocan.jp/mem } \\
\text { s-one }\end{array}$ \\
\hline CFD-ACE+ & ESI Group & http://www.esi-group.com \\
\hline Visual chip 3000 & Numerical Solutions & $\begin{array}{l}\text { http://www.numericalinnovati } \\
\text { ons.com }\end{array}$ \\
\hline ANSYS (13.0) & ANSYS, Inc & http://www.ansys.com/ \\
\hline $\begin{array}{l}\text { COMSOL Multiphysics® } \\
(4.0)\end{array}$ & COMSOL, Inc & http://www.cornsol.corn \\
\hline $\begin{array}{l}\text { Simplorer® (9.0) and } \\
\text { Maxwell® (14) }\end{array}$ & ANSOFT & http://www.ansoft.com \\
\hline 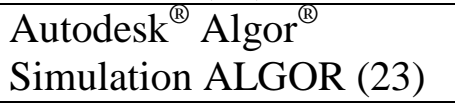 & Autodesk & http://www.autodesk.com \\
\hline $\begin{array}{l}\text { Abaqus FEA, Abaqus } \\
\text { Multiphysics and } \\
\text { SIMULIA SLM } \\
\end{array}$ & Dassault Systèmes SIMULIA & http://www.simulia.com \\
\hline $\begin{array}{l}\text { SUCCESS and SMASH - } \\
\text { with MEMS generators }\end{array}$ & DOLPHIN & http://www.dolphin.fr \\
\hline
\end{tabular}

* This list is developed to show variety for computer aided design (CAD) package selection and is not intended to be a comprehensive list of CAD software for microsystems. Each package consists of modules or software suites carrying out modelling and analysis sub-processes 
Table 2: Services delivered within microsystems production based on the product-service systems approach

\begin{tabular}{|c|c|c|c|c|}
\hline $\begin{array}{l}\text { Product/Service } \\
\text { Configuration }\end{array}$ & $\begin{array}{l}\text { Value } \\
\text { Proposition }\end{array}$ & Delivered services & $\begin{array}{l}\text { Product in value } \\
\text { proposition }\end{array}$ & $\begin{array}{l}\text { \% of sampled } \\
\text { companies }\end{array}$ \\
\hline \multirow[t]{4}{*}{ Product-oriented } & Product-related & $\begin{array}{l}\text { Sale of tools and machine with opened service channels for } \\
\text { maintenance and upgrades based on continuity in machine } \\
\text { and instrument production family lines. }\end{array}$ & $\begin{array}{l}\text { Micro-machinery, } \\
\text { Micro-instrument, } \\
\text { Device and Chip }\end{array}$ & 23 \\
\hline & \multirow[t]{3}{*}{$\begin{array}{l}\text { Advice/ } \\
\text { consultancy }\end{array}$} & $\begin{array}{l}\text { Consultancy and advice for microsystems manufacturers, } \\
\text { start-ups and technology }\end{array}$ & All & 74 \\
\hline & & $\begin{array}{l}\text { Design training for current/emerging design paradigms in } \\
\text { microsystems technology and for the use of computer-aided } \\
\text { design tools for the generation, simulation, verification and } \\
\text { validation of microsystems architectures and processes. }\end{array}$ & $\begin{array}{l}\text { Micro-instrument, } \\
\text { Device and Chip }\end{array}$ & 15 \\
\hline & & $\begin{array}{l}\text { Development training in the use of fabrication, analysis and } \\
\text { measuring tools and for expertise in microsystems } \\
\text { manufacturing technology. }\end{array}$ & $\begin{array}{l}\text { Micro-machinery and } \\
\text { Micro-instrument }\end{array}$ & 14 \\
\hline \multirow[t]{2}{*}{ Use-oriented } & Product lease & $\begin{array}{l}\text { Intellectual property leasing and computer-aided design } \\
\text { software licences backed with a support team to respond to } \\
\text { customer issues }\end{array}$ & All & 7 \\
\hline & $\begin{array}{l}\text { Product } \\
\text { renting/sharing }\end{array}$ & Foundry and instrument renting based on fixed agreements & $\begin{array}{l}\text { Micro-machinery and } \\
\text { Micro-instrument }\end{array}$ & 19 \\
\hline \multirow[t]{2}{*}{ Result-oriented } & $\begin{array}{l}\text { Activity } \\
\text { management// } \\
\text { outsourcing }\end{array}$ & $\begin{array}{l}\text { The main focus of fabless companies, marketers and } \\
\text { outsourcers. These companies act as intermediaries between } \\
\text { customers and manufacturers to deliver customer solutions. } \\
\text { Consortiums for creating alliances to manage production } \\
\text { for the delivery of customer solutions }\end{array}$ & All & 34 \\
\hline & $\begin{array}{l}\text { Pay per service } \\
\text { unit }\end{array}$ & $\begin{array}{l}\text { Foundry services for fabricating chips, packaging, } \\
\text { interconnections and assembly. }\end{array}$ & $\begin{array}{l}\text { Micro-machinery and } \\
\text { Micro-instrument }\end{array}$ & 32 \\
\hline
\end{tabular}


Table 3: Product-service system value propositions within microsystems production

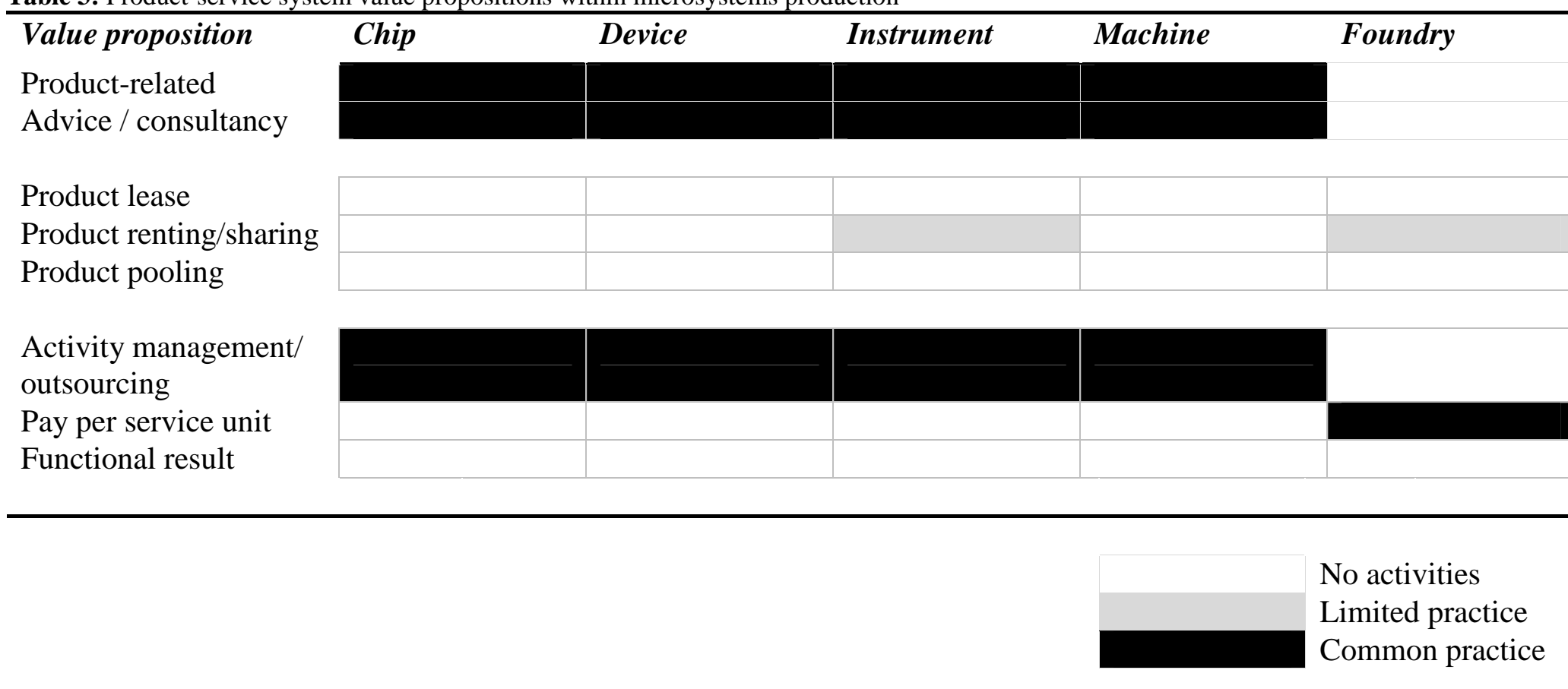


Table 4: Services to support microsystems product life -cycles

\begin{tabular}{|c|c|c|c|c|c|}
\hline Life-cycle perspective & Life-cycle phase services & Developers & Designers & Marketers & Consultants \\
\hline \multirow{4}{*}{ Product life cycle } & Engineering services & & & & \\
\hline & Production services & & & & \\
\hline & Usage services & & & & \\
\hline & Recycling/disposal services & & & & \\
\hline \multirow{6}{*}{ Manufacturer's view } & Product design services & & & & \\
\hline & Product manufacturing services & & & & \\
\hline & Spare parts manufacturing services & & & & \\
\hline & Product re-engineering services & & & & \\
\hline & Service design services & & & & \\
\hline & Servicing services & & & & \\
\hline \multirow{3}{*}{ User's view } & Product purchasing services & & & & \\
\hline & Product usage services & & & & \\
\hline & Product disposal services & & & & \\
\hline
\end{tabular}

